CLINICAL AND EXPERIMENTAL VACCINE RESEARCH

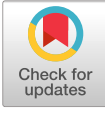

Clin Exp Vaccine Res 2019;8:94-102 https://doi.org/10.7774/cevr.2019.8.2.94 pISSN 2287-3651 • elSSN 2287-366X

Hoan-Jong Lee', Dae Sun Jo Yun-Kyung Kim ${ }^{3}$, Hyunju Lee ${ }^{4}$, Kyung-Hyo Kim ${ }^{5}$, Dokyung Lee ${ }^{6}$, Carlo Curina ${ }^{7}$, Marco Costantini ${ }^{7}$, Silvia Barbi ${ }^{8}$, Yan Miao ${ }^{8}$, Michele Pellegrini ${ }^{7}$

*A list author's affiliations appears at the end of the paper.

Received: June 17, 2019

Accepted: July 1, 2019

Corresponding author: Yan Miao, MD, PhD GSK, Hullenbergweg 81-89, 1101 CL, Amsterdam, The Netherlands

Tel: +31-2-05640564, Fax: +31-2-05640565

E-mail: yan.x.miao@gsk.com

This work was supported by GlaxoSmithKline Biologicals SA, which was the funding source and was involved in all stages of the study conduct and analysis. GlaxoSmithKline Biologicals SA also took responsibility for all costs associated with the development and publishing of the present manuscript. Hoan-Jong Lee's, Dae Sun Jo's and Hyunju Lee's institutions received grants from the GSK group of companies for the conduct of the study. Dokyung Lee, Carlo Curina, Marco Costantini, Silvia Barbi, Michele Pellegrini, and Yan Miao are employed by the GSK group of companies. Michele Pellegrini also holds shares in the GSK group of companies as part of his employee remuneration. Yun-Kyung Kim, and KyungHyo Kim have nothing to declare.

The authors would like to thank the children and their parents/legally representatives, study staff and Chiranjiwi Bhusal, Susanne Pittl, Sunil Swamy, and Wim Jansen (GSK) for their contribution to the study. The authors would also like to thank Petronela M. Petrar (Modis c/o GSK) for medical writing support and Adrian Kremer (Modis c/o GSK) for manuscript coordination and editorial support.

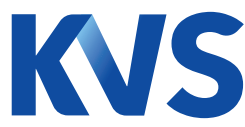
KOR E A N
VACCIN E
SOCI E T Y

(c) Korean Vaccine Society.

This is an Open Access article distributed under the terms of the Creative Commons Attribution Non-Commercial License (http://creativecommons.org/licenses/ by-nc/4.0) which permits unrestricted non-commercial use, distribution, and reproduction in any medium, provided the original work is properly cited.

\section{One-year antibody persistence and safety of a 4-dose schedule of MenACWY-CRM in healthy infants from South Korea}

Purpose: Results from a post-marketing study to generate evidence on 1-year antibody persistence and safety following vaccination of infants from South Korea with the quadrivalent meningococcal conjugate vaccine MenACWY-CRM.

Materials and Methods: In this phase IV, open-label, multi-center study (NCT02446691), 128 infants received MenACWY-CRM at ages 2, 4, 6, and 12 months. One-year antibody persistence following the full vaccination course was evaluated (primary objective) for the four meningococcal serogroups (Men) by serum bactericidal activity assay using human or rabbit complement (hSBA/rSBA). Immune responses at 1-month post-vaccination and safety were also assessed.

Results: The percentage of children with hSBA titers $\geq 8$ ranged between $94 \%(\mathrm{MenA})$ and $100 \%$ (MenY/W) 1-month post-vaccination, and from 39\% (MenA) to $89 \%$ (MenY) 1-year post-vaccination. At least $99 \%$ and $92 \%$ of children had rSBA titers $\geq 8$ and $\geq 128$ against each meningococcal serogroup, 1-month post-vaccination. One-year post-vaccination, the percentage of children with rSBA titers $\geq 8$ and $\geq 128$ ranged from $54 \%$ (MenC) to $99 \%$ (MenA) and from $30 \%$ (MenC) to $98 \%$ (MenA). Geometric mean titers declined from 1-month to 1-year postvaccination, when they varied between 6.8 (MenA) and 53.6 (MenW) by hSBA and between 17.2 (MenC) and 2,269.5 (MenA) by rSBA. At least one solicited and unsolicited adverse event was reported for $79 \%$ and $66 \%$ of children. Of 36 serious adverse events reported, none were vaccination-related.

Conclusion: Antibody persistence (hSBA/rSBA titers $\geq 8$ ) was determined in 39\%-99\% of children 1 year after a 4-dose MenACWY-CRM series during infancy, with an acceptable clinical safety profile.

Keywords: Quadrivalent meningococcal conjugate vaccine, MenACWY-CRM, Antibody persistence, Infants, Republic of Korea

\section{Introduction}

Invasive meningococcal disease (IMD) is a debilitating disease which, despite treatment, has fatality rates of $5 \%-10 \%$ and can induce serious, long-term, physical and neurological sequelae in up to $20 \%$ of survivors [1-3]. Therefore, IMD remains a major public concern, although disease incidence is relatively low [3,4]. Six of the 12 known serogroups of Neisseria meningitidis (MenA, MenB, MenC, MenW, MenX, and MenY) account for practically all IMD cases, but their prevalence varies considerably in time, 
by region and socio-economic status $[5,6]$.

In South Korea, where a national surveillance system is in place, the reported annual number of cases of meningococcal meningitis varied, with six cases documented in 2015 and in 2016, 17 in 2017 and 14 in 2018 [7]. The prevalence of meningococcal serogroups responsible for IMD also changed over time $[8,9]$. MenB was the most prominent serogroup between 2010 and 2016, accounting for 37\% of IMD cases, while MenW was responsible for small outbreaks in military personnel, prior to the initiation of a meningococcal vaccination program in 2012 [9].

Vaccination remains the most effective and safe approach to prevent IMD [4]. In South Korea, two quadrivalent meningococcal vaccines are licensed. The MenACWY-CRM (GSK Vaccines Srl, Bellaria-Rosia, Italy) vaccine, conjugated with a non-toxic mutant of Corynebacterium diphtheriae toxin, in individuals 2 months-55 years, and a diphtheria toxoid-conjugate vaccine (Sanofi Pasteur Inc., Swiftwater, PA, USA), for use in individuals 9 months- 55 years of age.

MenACWY-CRM has been shown to be immunogenic and well-tolerated in all ages where indicated [10]. Protective levels of antibodies against meningococcal serogroups were shown to persist to various degrees up to 5 years post-vaccination, in infants and toddlers [11,12], children 2-10 years of age $[13,14]$, adolescents and adults [15-17]. However, their decline over time varies with the serogroup, age group, and the serum bactericidal activity assay (SBA) used to evaluate antibody response, either using human or rabbit (hSBA/rSBA) complement [18].

This study was conducted to generate evidence on 1-year antibody persistence and safety following MenACWY-CRM vaccination of infants from South Korea, after the vaccine's indication extended in the country to this age group in May 2014.

\section{Materials and Methods}

\section{Study design and participants}

This phase IV, open-label study was conducted in six centers in South Korea, from July 2015 to December 2017. Healthy 2-month-old infants were eligible for enrollment if their parents/legally acceptable representatives provided written informed consent and were able and willing to comply with the study procedures, as assessed by the investigators. Infants who previously received any meningococcal vaccines, had a confirmed or suspected case of meningococcal disease, or had household contact/intimate exposure to a person with laboratory-confirmed $N$. meningitidis infection were not eligible for enrollment. A full list of inclusion and exclusion criteria is provided in Supplementary Material.

Infants received a 4-dose vaccination series with MenACWY-CRM, administered at study months $0,2,4$, and 10, corresponding to 2, 4, 6, and 12 months of age (Fig. 1). Eligibility criteria were checked prior to each vaccine administration.

The vaccine's composition was previously described in detail [19]. Each dose $(0.5 \mathrm{~mL})$ was administered according to the prescribing information.

\section{Study objectives}

The primary objective was to evaluate the persistence of antibody responses against MenA, MenC, MenW, and MenY, measured by the percentages of participants with hSBA titers $\geq 8$, as well as rSBA titers $\geq 8$ and $\geq 128$, at 1 year after the completion of the 4-dose vaccination series. Secondary objectives were to assess immune responses to MenACWY-CRM vaccination in terms of hSBA and rSBA geometric mean titers (GMTs) at 1-month and 1-year post-vaccination, as well as the percentages of participants with hSBA titers $\geq 8$, rSBA titers $\geq 8$ and $\geq 128$ at 1 month after the completion of the 4 -dose series.

The safety and tolerability of MenACWY-CRM were also assessed.

\section{Immunogenicity assessment}

For each participant, blood samples (approximately $5 \mathrm{~mL}$ per draw) were collected at 1 month and 1 year after the last vaccine dose (Fig. 1) and tested using hSBA and rSBA, as previously described $[20,21]$. Testing was performed at the GSK Clinical Sciences Laboratory, Marburg, Germany (hSBA) and at Public Health England, UK (rSBA). The percentages of participants with hSBA titers $\geq 8$ and $\mathrm{rSBA} \geq 8$ and $\geq 128$, as well as hSBA and rSBA GMTs, were measured at both time points.

\section{Safety and reactogenicity assessment}

Solicited local adverse events (AEs; injection site erythema, induration, and tenderness) and systemic AEs (change in eating habits, sleepiness, irritability, vomiting, diarrhea, fever [body temperature $\geq 38.0^{\circ} \mathrm{C}$ ]) were recorded within 7 days (days 0-6) following each MenACWY-CRM dose. Use of analgesics/antipyretics during the 7-day period post-vaccination was also recorded. Unsolicited AEs, medically-attended AEs, AEs leading to withdrawal from the study, and serious AEs (SAEs) were recorded throughout the study. 


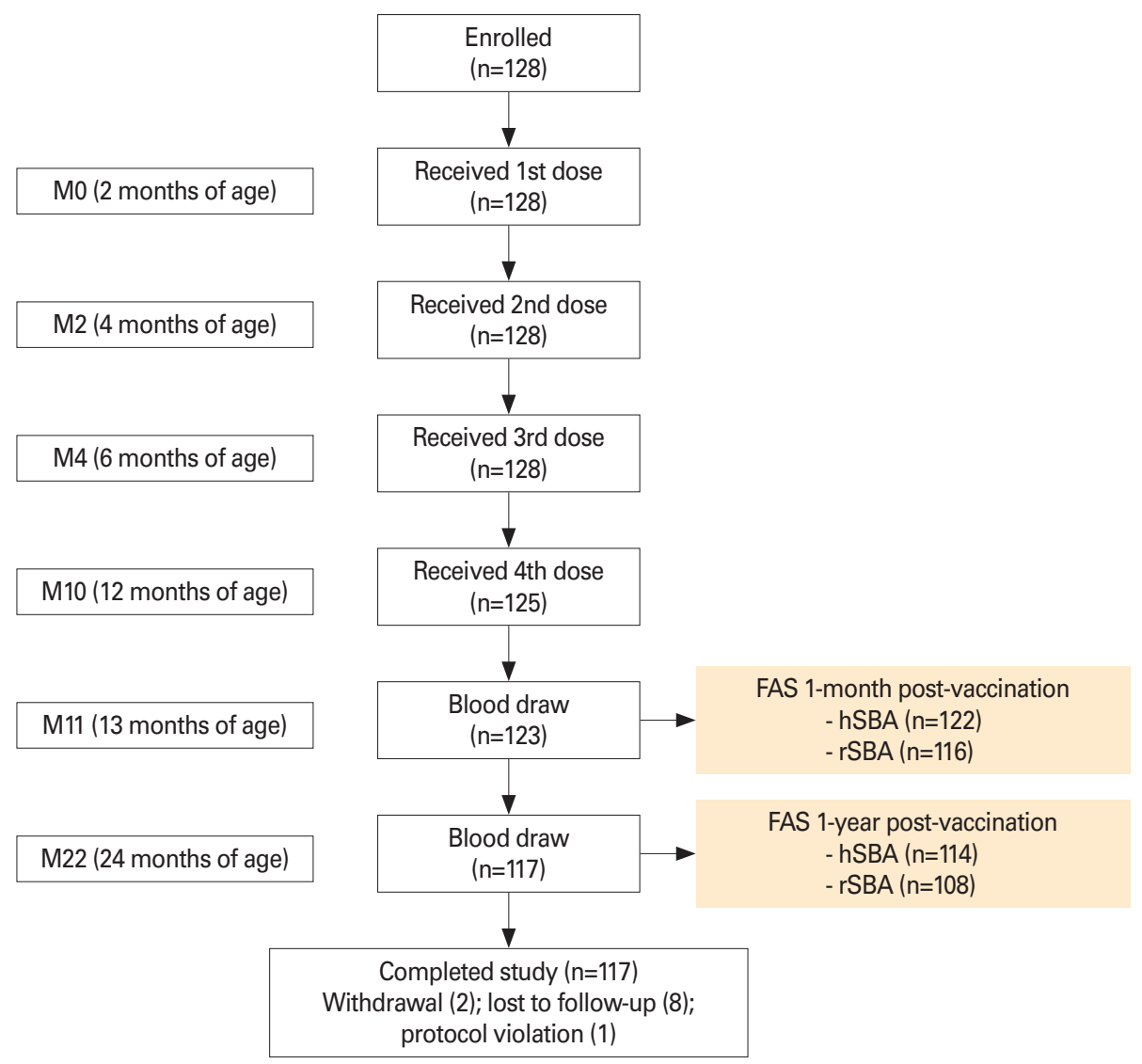

Fig. 1. Participant flow chart. $M$, study month; FAS, full analysis set; hSBA, serum bactericidal assay using human complement; rSBA, serum bactericidal assay using rabbit complement.

All AEs were graded by severity as mild (transient with no limitation in normal daily activity), moderate (some limitation in normal daily activity) or severe (diameter $>50 \mathrm{~mm}$ for injection site erythema and induration, temperature $\geq 40^{\circ} \mathrm{C}$ for fever, and preventing normal daily activity for all other AEs). The relationship to study vaccination (not related, possibly related, or probably related) was assessed by the investigator for unsolicited AEs and SAEs.

\section{Statistical analyses}

A sample size of 100 evaluable infants was requested by the South Korean health authority; assuming a 25\% drop-out rate, a total of approximately 135 infants were to be enrolled in the study.

Immunogenicity analyses for primary and secondary objectives were conducted on the full analysis set (FAS), which included participants who received at least one vaccine dose and had available immunogenicity data at relevant time points. Immunogenicity analyses were also carried out in the per protocol set (PPS), which included FAS participants with no major protocol deviations. Safety analyses were performed on participants who received at least one vaccine dose and had relevant available safety data (solicited and unsolicited safety sets).

Persistence of the antibody response was summarized as the percentage of participants with $\mathrm{hSBA} / \mathrm{rSBA}$ titers above the pre-specified thresholds, along with associated 2-sided 95\% Clopper-Pearson confidence intervals (CIs) [22].

Titers below the assay's limit of detection were set at half the limit. Antibody GMTs with 2-sided 95\% CIs were constructed by exponentiating (base 10) the means and CIs of the $\log _{10^{-}}$ transformed antibody titer. Geometric mean ratios (GMRs) between GMTs at 1 year and 1 month after completion of the vaccination schedule were calculated with 2 -sided $95 \%$ CIs.

All statistical analyses were performed using SAS Institute Inc. (Cary, NC, USA).

\section{Trademark statement}

Menveo is a trademark licensed to or owned by the GSK group of companies. Menactra is a trademark of Sanofi Pasteur. 


\section{Data sharing statement}

The results summary for this study (GSK study number 205336NCT02446691) is available on the GSK Clinical Study Register and can be accessed at www.gsk-clinicalstudyregister.com. For interventional studies that evaluate our medicines, anonymized patient-level data will be made available to independent researchers, subject to review by an independent panel, at www.clinicalstudydatarequest.com within 6 months of publication. To protect the privacy of patients and individuals involved in our studies, GSK does not publicly disclose patientlevel data.

\section{Ethics statement}

The study protocol was approved by the institutional review boards (IRBs) of Seoul National University Hospital (IRB No. H-1503-079-656), Inha University Hospital (IRB No. 15-027), Ewha Womans University Mokdong Hospital (IRB No. EUMC 2015-03-006), Korea University Ansan Hospital (IRB No. AS15012), Chonbuk National University Hospital (IRB No. CUH 201503-037) and Seoul National University Bundang Hospital (IRB No. B-1504/293-006). Informed consent was confirmed by the IRBs. The study was conducted in compliance with the Declaration of Helsinki and followed International Committee on Harmonization Guidelines for Good Clinical Practice and is registered at www.clinicaltrials.gov (NCT02446691).

\section{Results}

\section{Demographics}

A total of 128 infants were enrolled in the study. All received at least one MenACWY-CRM dose, and 117 completed the study (Fig. 1). Most infants who did not complete the study were lost to follow up. No premature withdrawals were caused by an AE.

The mean age of the infants at enrollment was 71.7 days. Overall, $54 \%$ of participants were male and $46 \%$ female. All infants but one ( $>99 \%$ ) were Asian (Table 1 ).

\section{Human serum bactericidal activity results}

At 1 month after full vaccination with MenACWY-CRM, the percentage of participants with hSBA titers $\geq 8$ ranged between 94\% (MenA) and 100\% (MenW and MenY). At 1-year post-vaccination (the timepoint of the primary immunogenicity objective), these percentages were $39 \%$ for MenA, $61 \%$ for MenC, $\mathbf{8 8 \%}$ for MenW, and 89\% for MenY (Fig. 2A, Supplementary Table 1).

At 1-month post-vaccination, hSBA GMTs varied from 107.9 (MenA) to 426.7 (MenW) and at 1-year post-vaccination, they ranged from 6.8 (MenA) to 53.6 (MenW) (Fig. 2B, Supplemen-

Table 1. Participants' characteristics at enrolment

\begin{tabular}{lc}
\hline & Enrolled set $(\mathrm{n}=128)$ \\
\hline Age (day) & $71.7 \pm 8.1$ \\
Female sex & $59(46)$ \\
Race & \\
Asian & $127(99)$ \\
Other & $1(1)$ \\
Weight $(\mathrm{kg})$ & $6.1 \pm 0.7$ \\
Height $(\mathrm{cm})$ & $59.5 \pm 2.7$
\end{tabular}

Values are presented as mean $\pm S D$ or number $(\%)$.

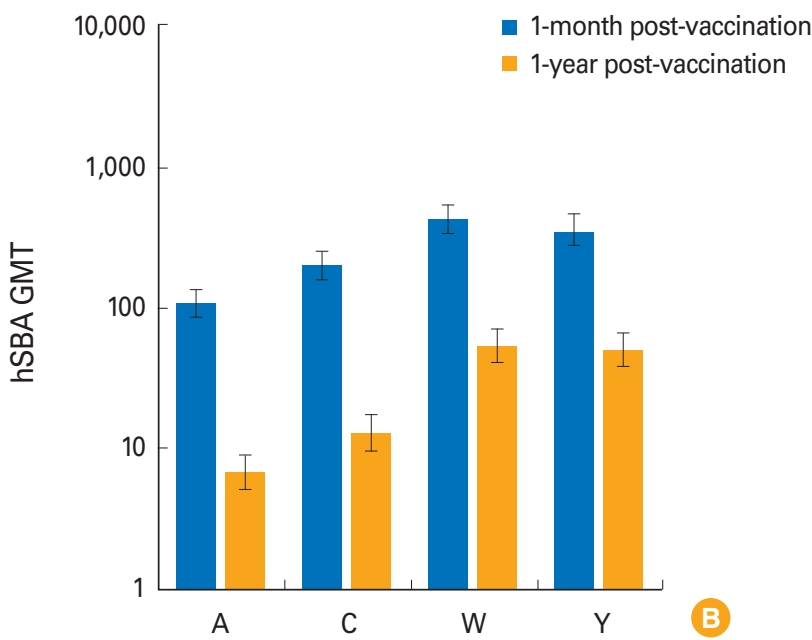

Fig. 2. (A, B) Immune responses evaluated using hSBA (full analysis set). hSBA, serum bactericidal assay using human complement; GMT, geometric mean titer; A, MenA; C, MenC; W, MenW; Y, MenY. Error bars represent 95\% confidence intervals. 
Hoan-Jong Lee et al • One-year antibody persistence following MenACWY-CRM vaccination in South Korean infants

tary Table 1). The reverse cumulative distribution of hSBA titers is presented in Supplementary Fig. 1. One-year versus 1-month post-vaccination GMRs ranged from 0.061 (MenA), and 0.14 (MenY) (Supplementary Table 1).

\section{Rabbit serum bactericidal activity results}

At 1-month post-vaccination, $\geq 99 \%$ of children had rSBA titers $\geq 8$ and $\geq 92 \%$ had titers $\geq 128$ against each of the four meningococcal serogroups. At 1-year post-vaccination, the timepoint of the primary immunogenicity objective, the percentage of children with rSBA titers $\geq 8$ was $54 \%$ for MenC, $69 \%$ for MenW, $90 \%$ for MenY and 99\% for MenA; percentages of participants with rSBA titers $\geq 128$ ranged between $30 \%$ (MenC) and 98\% (MenA) (Fig. 3A, Supplementary Table 2).

rSBA GMTs ranged from 735.1 (MenC) to 7,394.2 (MenA) at 1-month post-vaccination, and from 17.2 (MenC) to 2,269.5 (MenA) at 1-year post-vaccination (Fig. 3B, Supplementary Table 2). The reverse cumulative distribution of rSBA titers is presented in Supplementary Fig. 2. GMRs varied by serogroup, from 0.019 to 0.32 (Supplementary Table 2).

Immunogenicity results for the PPS were similar to those obtained for the FAS (Supplementary Table 3).

\section{Safety and reactogenicity}

Overall, at least one solicited AE was reported for $79 \%$ of children (38\% for local AEs and $78 \%$ for systemic AEs), after any vaccine dose. The most frequently reported solicited local $\mathrm{AE}$ after each vaccination was injection-site tenderness, for $11 \%$ $16 \%$ of participants. The most frequently solicited systemic
AEs were irritability, reported for $36 \%-45 \%$ of children, and sleepiness, reported for $16 \%-41 \%$ of children, across all vaccinations. Most solicited AEs were mild or moderate in nature, with severe solicited AEs being reported for $\leq 4 \%$ of children (Table 2).

Table 2. Number and percentage of participants with reported solicited adverse events within the 7-days period after each vaccine dose (solicited safety set)

\begin{tabular}{lcccc}
\hline & $\begin{array}{c}1 \text { st dose } \\
(\mathrm{n}=128)\end{array}$ & $\begin{array}{c}2 \mathrm{nd} \mathrm{dose} \\
(\mathrm{n}=128)\end{array}$ & $\begin{array}{c}\text { 3rd dose } \\
(\mathrm{n}=127)\end{array}$ & $\begin{array}{c}\text { 4th dose } \\
(\mathrm{n}=124)\end{array}$ \\
\hline Local adverse event & & & & \\
Erythema & $4(3)$ & $6(5)$ & $1(1)$ & $6(5)$ \\
Severe & 0 & 0 & $1(1)$ & $2(2)$ \\
Induration & $4(3)$ & $9(7)$ & $3(2)$ & $6(5)$ \\
Severe & 0 & 0 & 0 & $2(2)$ \\
Tenderness & $17(13)$ & $21(16)$ & $14(11)$ & $20(16)$ \\
Severe & 0 & 0 & $3(2)$ & $2(2)$ \\
Systemic adverse event & & & & \\
Change in eating habits & $29(23)$ & $21(16)$ & $21(17)$ & $24(19)$ \\
Severe & $2(2)$ & 0 & 0 & $3(2)$ \\
Sleepiness & $52(41)$ & $31(24)$ & $28(22)$ & $20(16)$ \\
Severe & $2(2)$ & 0 & 0 & $4(3)$ \\
Irritability & $58(45)$ & $49(38)$ & $47(37)$ & $45(36)$ \\
Severe & $2(2)$ & $3(2)$ & $4(3)$ & $5(4)$ \\
Vomiting & $26(20)$ & $20(16)$ & $15(12)$ & $5(4)$ \\
Severe & 0 & $1(1)$ & 0 & $1(1)$ \\
Diarrhea & $15(12)$ & $13(10)$ & $15(12)$ & $17(14)$ \\
Severe & 0 & $1(1)$ & 0 & 0 \\
Fever $\left(\geq 38^{\circ} \mathrm{C}\right)$ & $4(3)$ & $10(8)$ & $6(5)$ & $15(12)$ \\
\hline
\end{tabular}

Values are presented as number (\%).

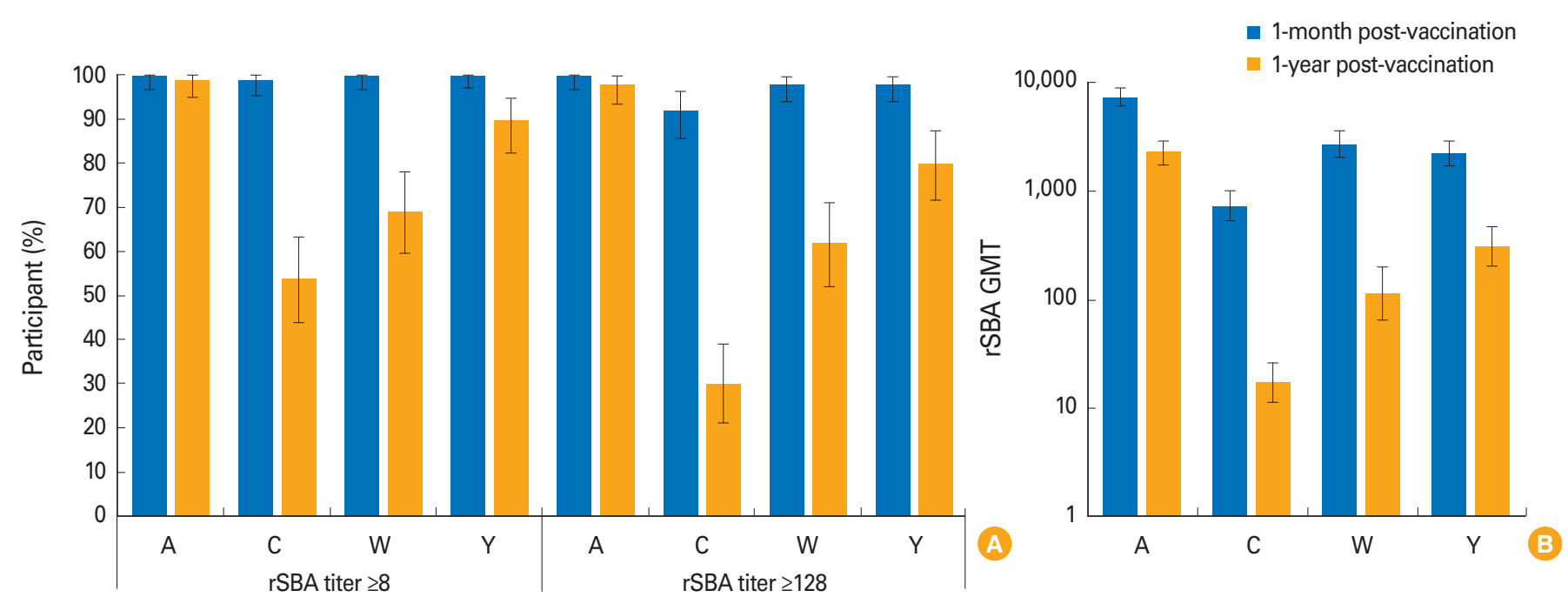

Fig. 3. (A, B) Immune responses evaluated using rSBA (full analysis set). rSBA, serum bactericidal assay using rabbit complement; GMT, geometric mean titer; A, MenA; C, MenC; W, MenW; Y, MenY. Error bars represent 95\% confidence intervals. 
Table 3. Number and percentage of participants with reported unsolicited adverse events after any vaccination, up to study end (unsolicited safety set, $n=128$ )

\begin{tabular}{lc}
\hline & No. (\%) \\
\hline Any unsolicited AEs & $85(66)$ \\
At least possibly related & $1(1)$ \\
SAEs & $26(20)$ \\
At least possibly related & 0 \\
Medically attended AEs & $85(66)$ \\
At least possibly related & $1(1)$ \\
AEs leading to withdrawal & 0 \\
AEs leading to death & 0
\end{tabular}

$A E$, adverse event; $S A E$, serious AE.

At least one unsolicited $\mathrm{AE}$ was reported for 85 children (66\%); all were medically-attended and one AE (diarrhea) was considered as possibly related to vaccination (Table 3 ). The most frequent unsolicited AEs were upper respiratory tract infection, reported in 34 children (27\%), bronchiolitis in 15 children (12\%), and nasopharyngitis in 15 children (12\%). Most unsolicited AEs were mild to moderate in intensity and resolved before study termination.

Throughout the study, a total of 36 SAEs (detailed in Supplementary Table 4 ) were reported in 26 children (20\%). All were recovered/resolved by the end of study and none was assessed as related to vaccination (Table 3). There were no deaths reported during the study.

\section{Discussion}

In the absence of circulating bactericidal antibodies, meningococcal disease can progress so rapidly that otherwise healthy individuals can become severely ill or can die within a few hours. This study is the first to assess, using both hSBA and rSBA, the antibody persistence at 1 year following a 4-dose infant priming series of MenACWY-CRM. Infant priming with the quadrivalent meningococcal CRM-conjugate vaccine elicited levels of bactericidal antibodies assumed to be protective against three epidemiologically relevant serogroups (MenC, MenW, and MenY) that were maintained for at least 1 year in $\geq 54 \%$ of children. When persistence of immune responses was assessed against MenA, the percentage of participants with SBA titers $\geq 8$ was lower when tested by hSBA than by rSBA (39\% vs. 99\%) 1-year post-vaccination.

The antibody persistence observed in this South Korean study is similar to that reported from a previous study con- ducted in the United States, which showed a wane in seroprotection rates, at 60 months following a 4-dose MenACWYCRM infant schedule [18]. Across MenCWY serogroups, the percentages of participants with SBA titers $\geq 8$ ranged between $26 \%$ (MenC) and 68\% (MenW) with hSBA, and between $27 \%$ (MenC) and $71 \%$ (MenY) with rSBA. However, as in the current study, the decline was more pronounced for MenA when the hSBA was used ( $6 \%$ of participants with titers $\geq 8$, compared to $96 \%$ of participants with rSBA titers $\geq 8$ ) [18].

A similar observation showing no correlation between hSBA and rSBA for MenA was reported in a study evaluating the antibody persistence at 3 years after MenACWY-CRM vaccine administration in adolescents [15]. The percentages of participants with hSBA titers $\geq 8$ against MenA were lower when assessed by hSBA (28\%) compared with rSBA (96\%). Similar results were observed in the same study when the antibody persistence to the comparator vaccine MenACWY-D was tested using the two assays [15]. The wane in hSBA titers and the relative lower percentages of participants with protective antibody levels $(\geq 8)$ especially against MenA seem to constitute an assay-specific phenomenon which is not also observed when using rSBA.

While hSBA has been widely used to assess immune responses, there is mounting evidence that use of human complement in the SBA may not be optimal for assessing longterm antibody persistence, especially against MenA. Use of the baby rabbit complement SBA may be more appropriate [23], and the rSBA assay is also included in the World Health Organization-recommended procedure for evaluation of meningococcal vaccines [20]. The differences between rSBA and hSBA titers are thought to be due, at least partially, to meningococcal factor $\mathrm{H}$ binding protein, which binds specifically to human factor $\mathrm{H}$ to ultimately enable evasion of complementmediated killing. Relatedly, it has been shown that human antibody subclasses may differentially interact with human and rabbit complement [23].

The immunogenicity results obtained in the current trial at 1-month post-MenACWY-CRM vaccination are also consistent with previous studies in infants. In a pivotal study in the United States where infants received the same vaccination schedule, $94 \%-100 \%$ of children had hSBA titers $\geq 8$ against each of the meningococcal serogroups 1 month after schedule completion [24]. In another clinical trial, 96\%-99\% of infants had hSBA titers $\geq 8$ against all four serogroups at 1 month following vaccination with four MenACWY-CRM doses, administered at 2, 4, 6, and 12 months of age [25]. Similar results 
Hoan-Jong Lee et al • One-year antibody persistence following MenACWY-CRM vaccination in South Korean infants

were also observed following a 3-dose series of MenACWYCRM, with $89 \%-98 \%$ of infants achieving hSBA titers $\geq 8$ at 1-month post-vaccination [26]. All these trials also demonstrated that co-administration of MenACWY-CRM with routine pediatric vaccines did not impact the immune responses against meningococcal serogroups.

Safety data collected in the current study were similar with those from previous reports in infants after a vaccination with MenACWY-CRM in infants [24,26,27]. These consistent results further confirm the acceptable clinical safety profile observed in all studied age groups, including in Asian populations [28-30].

Potential limitations of the study included the fact that baseline antibody levels were not evaluated; however, the magnitude of immune responses against all serogroups at 1-month post-vaccination with MenACWY-CRM were consistent with the evidence generated from previous studies in infants [10].

In view of the dynamic epidemiology of IMD and its potential severe, long-term sequalae, vaccination against all meningococcal serogroups, including MenA, MenC, MenW, and MenY remains important for public health, even considering the relatively low disease incidence in South Korea.

In conclusion, a 4-dose infant priming vaccination series with MenACWY-CRM was able to induce robust immune responses in infants from South Korea, and hSBA/rSBA titers $\geq 8$ for all four meningococcal serogroups were sustained in $39 \%-99 \%$ of children up to 1 year after schedule completion. No new concerns were raised with respect to the safety and tolerability of MenACWY-CRM.

\section{ORCID}

Hoan-Jong Lee https://orcid.org/0000-0001-9643-3692

Dae Sun Jo https://orcid.org/0000-0002-3141-9539

Yun-Kyung Kim https://orcid.org/0000-0003-4396-8671

Hyunju Lee https://orcid.org/0000-0003-0107-0724

Kyung-Hyo Kim https://orcid.org/0000-0002-0333-6808

Dokyung Lee https://orcid.org/0000-0003-3123-6086

Carlo Curina https://orcid.org/0000-0002-3536-124X

Marco Costantini https://orcid.org/0000-0003-4709-2590

Silvia Barbi https://orcid.org/0000-0002-3996-7361

Yan Miao https://orcid.org/0000-0002-7728-3112

Michele Pellegrini https://orcid.org/0000-0001-8505-9260

\section{Author Details}

${ }^{1}$ Department of Pediatrics, Seoul National University College of Medicine, Seoul National University Children's Hospital, Seoul; ${ }^{2}$ Department of Pediatrics, Chonbuk National University Medical School, Chonbuk National University Children's Hospital, Jeonju; ${ }^{3}$ Department of Pediatrics, Korea University College of Medicine, Korea University Ansan Hospital, Ansan; ${ }^{4}$ Department of Pediatrics, Seoul National University College of Medicine, Seoul National University Bundang Hospital, Seongnam; ${ }^{5}$ Department of Pediatrics, Ewha Womans University College of Medicine, Ewha Womans University Mokdong Hospital, Seoul; ${ }^{6} \mathrm{GSK}$, Seoul, Korea; ${ }^{7} \mathrm{GSK}$, Siena, Italy; ${ }^{8} \mathrm{GSK}$, Amsterdam, The Netherlands

\section{Supplementary Material}

Supplementary materials are available at Clinical and Experimental Vaccine Research website (http://www.ecevr.org).

\section{References}

1. Dwilow R, Fanella S. Invasive meningococcal disease in the 21st century: an update for the clinician. Curr Neurol Neurosci Rep 2015;15:2.

2. Olbrich KJ, Muller D, Schumacher S, Beck E, Meszaros K, Koerber F. Systematic review of invasive meningococcal disease: sequelae and wuality of life impact on patients and their caregivers. Infect Dis Ther 2018;7:421-38.

3. World Health Organization. Meningococcal meningitis: key facts [Internet]. Geneva: World Health Organization; 2018 [cited 2019 Apr 24]. Available from: http://www.who. int/en/news-room/fact-sheets/detail/meningococcalmeningitis.

4. Meningococcal vaccines: WHO position paper, November 2011. Wkly Epidemiol Rec 2011;86:521-39.

5. Pelton SI. The global evolution of meningococcal epidemiology following the introduction of meningococcal vaccines. J Adolesc Health 2016;59(2 Suppl):S3-S11.

6. World Health Organization. Invasive meningococcal disease: serogroup distribution [Internet]. Geneva: World Health Organization; 2018 [cited 2019 Apr 24]. Available from: http://www.who.int/emergencies/diseases/meningitis/serogroup-distribution-2018.pdf?ua=1.

7. Korea Centers for Disease Control and Prevention. Disease surveillance statistics. Public Health Weekly Report. Vol 12, No. 11 [Internet]. Cheonju: Korea Centers for Disease Control and Prevention; 2019 [cited 2019 Apr 24]. Available from: http://www.cdc.go.kr/CDC/eng/info/Cdc- 
KeDIDO.jsp?menuIds=HOME002-MNU0576-MNU0583 \&fid $=9712 \&$ q_type $=\&$ q_value $=\&$ cid $=143274 \&$ pageNum $=$. 8. Kim SA, Kim DW, Dong BQ, Kim JS, Anh DD, Kilgore PE. An expanded age range for meningococcal meningitis: molecular diagnostic evidence from population-based surveillance in Asia. BMC Infect Dis 2012;12:310.

9. Lee H, Seo Y, Kim KH, Lee K, Choe KW. Prevalence and serogroup changes of Neisseria meningitidis in South Korea, 2010-2016. Sci Rep 2018;8:5292.

10. Keshavan P, Pellegrini M, Vadivelu-Pechai K, Nissen M. An update of clinical experience with the quadrivalent meningococcal ACWY-CRM conjugate vaccine. Expert Rev Vaccines 2018;17:865-80.

11. Khatami A, Snape MD, Davis E, et al. Persistence of the immune response at 5 years of age following infant immunisation with investigational quadrivalent MenACWY conjugate vaccine formulations. Vaccine 2012;30:2831-8.

12. Klein NP, Block SL, Johnston W, et al. 1085: Persistence of meningococcal bactericidal antibodies and booster response at 60-months of age in children who received infant or toddler doses of MenACWY-CRM conjugate vaccine. Open Forum Infect Dis 2014;1(Suppl 1):S319.

13. Block SL, Christensen S, Verma B, et al. Antibody persistence 5 years after vaccination at 2 to 10 years of age with Quadrivalent MenACWY-CRM conjugate vaccine, and responses to a booster vaccination. Vaccine 2015;33:217582.

14. Johnston W, Essink B, Kirstein J, et al. Comparative assessment of a single dose and a 2-dose vaccination series of a quadrivalent meningococcal CRM-conjugate vaccine (MenACWY-CRM) in children 2-10 years of age. Pediatr Infect Dis J 2016;35:e19-27.

15. Baxter R, Reisinger K, Block SL, Izu A, Odrljin T, Dull P. Antibody persistence and booster response of a quadrivalent meningococcal conjugate vaccine in adolescents. J Pediatr 2014;164:1409-15.e4.

16. Baxter R, Reisinger K, Block SL, et al. Antibody persistence after primary and booster doses of a quadrivalent meningococcal conjugate vaccine in adolescents. Pediatr Infect Dis J 2014;33:1169-76.

17. Jacobson RM, Jackson LA, Reisinger K, Izu A, Odrljin T, Dull PM. Antibody persistence and response to a booster dose of a quadrivalent conjugate vaccine for meningococcal disease in adolescents. Pediatr Infect Dis J 2013;32: el70-7.

18. Baxter R, Keshavan P, Welsch JA, Han L, Smolenov I. Per- sistence of the immune response after MenACWY-CRM vaccination and response to a booster dose, in adolescents, children and infants. Hum Vaccin Immunother 2016;12:1300-10.

19. Highlights of prescribing information: Menveo [Internet]. Silverspring: U.S. Food and Drug Administration; 2018 [cited 2019 Apr 24]. Available from: http://www.fda.gov/ downloads/biologicsbloodvaccines/vaccines/approvedproducts/ucm201349.pdf.

20. Maslanka SE, Gheesling LL, Libutti DE, et al. Standardization and a multilaboratory comparison of Neisseria meningitidis serogroup $\mathrm{A}$ and $\mathrm{C}$ serum bactericidal assays. The Multilaboratory Study Group. Clin Diagn Lab Immunol 1997;4:156-67.

21. Snape MD, Perrett KP, Ford KJ, et al. Immunogenicity of a tetravalent meningococcal glycoconjugate vaccine in infants: a randomized controlled trial. JAMA 2008;299:17384.

22. Clopper CJ, Pearson ES. The use of confidence or fiducial limits illustrated in the case of the binomial. Biometrika 1934;26:404-13.

23. Findlow J, Balmer P, Borrow R. A review of complement sources used in serum bactericidal assays for evaluating immune responses to meningococcal ACWY conjugate vaccines. Hum Vaccin Immunother 2019 Mar 18 [Epub]. https://doi.org/10.1080/21645515.2019.1593082.

24. Klein NP, Reisinger KS, Johnston W, et al. Safety and immunogenicity of a novel quadrivalent meningococcal CRMconjugate vaccine given concomitantly with routine vaccinations in infants. Pediatr Infect Dis J 2012;31:64-71.

25. Block SL, Shepard J, Garfield H, et al. Immunogenicity and safety of a 3- and 4-dose vaccination series of a meningococcal ACWY conjugate vaccine in infants: results of a phase $3 \mathrm{~b}$, randomized, open-label trial. Pediatr Infect Dis J 2016;35:e48-59.

26. Tregnaghi M, Lopez P, Stamboulian D, et al. Immunogenicity and safety of a quadrivalent meningococcal polysaccharide CRM conjugate vaccine in infants and toddlers. Int J Infect Dis 2014;26:22-30.

27. Klein NP, Shepard J, Bedell L, Odrljin T, Dull P. Immunogenicity and safety of a quadrivalent meningococcal conjugate vaccine administered concomitantly with measles, mumps, rubella, varicella vaccine in healthy toddlers. Vaccine 2012;30:3929-36.

28. Huang LM, Chiu NC, Yeh SJ, Bhusal C, Arora AK. Immunogenicity and safety of a single dose of a CRM-conjugat- 
Hoan-Jong Lee et al • One-year antibody persistence following MenACWY-CRM vaccination in South Korean infants

ed meningococcal ACWY vaccine in children and adolescents aged 2-18 years in Taiwan: results of an open label study. Vaccine 2014;32:5177-84.

29. Lalwani S, Agarkhedkar S, Gogtay N, et al. Safety and immunogenicity of an investigational meningococcal ACWY conjugate vaccine (MenACWY-CRM) in healthy Indian subjects aged 2 to 75 years. Int J Infect Dis 2015;38:36-42.

30. Lee HJ, Chung MH, Kim WJ, et al. Immunogenicity and safety of a novel quadrivalent meningococcal conjugate vaccine (MenACWY-CRM) in healthy Korean adolescents and adults. Int J Infect Dis 2014;28:204-10. 


\section{Supplemental Material}

\section{Study inclusion/exclusion criteria}

\section{Inclusion criteria}

Infants had to meet all the following criteria to be included in the study.

- Healthy male and female 2-month-old infants at time of consent

- Infants whose parents or legal guardians voluntary gave written informed consent after the nature of the study was explained according to local regulatory requirements, prior to study entry

- Infants whose parents or legal guardians would comply with study procedures including follow-up

\section{Exclusion criteria}

Infants meeting any of the following criteria were not included in the study.

- Previously received any meningococcal A, C, W, and Y vaccines

- Previous confirmed or suspected disease caused by Neisseria meningitidis or who have had household contact with and/or intimate exposure to an individual with laboratory confirmed $N$. meningitidis infection at any time since birth

- Progressive, unstable, or uncontrolled clinical conditions

- History of anaphylactic shock, asthma, urticarial, or other allergic reaction after previous vaccinations or known hypersensitivity to any vaccine component

- Experienced significant acute or chronic infection within 7 days before enrollment or had experienced fever (temperature $\geq 38.0^{\circ} \mathrm{C}$ ) within 3 days before enrollment

- Confirmed or suspected immunosuppressive or immunodeficient condition, based on medical history and physical examination

- Received treatment with systemic administration of corticosteroids for more than 14 consecutive days from birth

- Received blood, blood products and/or plasma derivatives or any parenteral immunoglobulin preparation at any time since birth

- Bleeding disorders considered as a contraindication to intra muscular injection or blood draw

- Any condition which, in the opinion of the investigator, might interfere with the results of the study or pose additional risk to the participant due to inclusion in the study

- Received or planned to receive any investigational or non-registered medicinal product from birth and throughout the study period

- Received oral or parenteral antibiotic treatment the 77 days prior to the scheduled blood draws (topical antibiotics were acceptable, including antibiotic eye drops)

- Were relatives of site research staff working on the study 
Hoan-Jong Lee et al • One-year antibody persistence following MenACWY-CRM vaccination in South Korean infants

Supplementary Table 1. Summary of hSBA immunogenicity results (hSBA full analysis set)

\begin{tabular}{|c|c|c|c|c|}
\hline & No. & Participants with titers $\geq 8(95 \% \mathrm{Cl}, \%)$ & $\mathrm{GMT}(95 \% \mathrm{CI})$ & $\mathrm{GMR}^{\mathrm{a})}(95 \% \mathrm{CI})$ \\
\hline \multicolumn{5}{|l|}{ MenA } \\
\hline $1 \mathrm{M}$ post-vac & 122 & 94 (88.5-97.7) & $107.9(85.7-135.8)$ & $0.061(0.048-0.076)$ \\
\hline $1 Y$ post-vac & 114 & $39(30.4-49.1)$ & $6.8(5.2-8.9)$ & \\
\hline \multicolumn{5}{|l|}{ MenC } \\
\hline $1 \mathrm{M}$ post-vac & 122 & 98 (94.2-99.8) & $201.0(157.9-256.0)$ & $0.063(0.049-0.080)$ \\
\hline 1Y post-vac & 110 & 61 (51.1-70.1) & $13.0(9.7-17.6)$ & \\
\hline \multicolumn{5}{|l|}{ MenW } \\
\hline $1 \mathrm{M}$ post-vac & 122 & $100(97.0-100.0)$ & 426.7 (338.3-538.2) & $0.12(0.099-0.15)$ \\
\hline $1 Y$ post-vac & 113 & 88 (80.1-93.1) & $53.6(40.4-71.0)$ & \\
\hline \multicolumn{5}{|l|}{ MenY } \\
\hline $1 \mathrm{M}$ post-vac & 120 & $100(97.0-100.0)$ & $359.4(280.6-460.3)$ & $0.14(0.11-0.16)$ \\
\hline $1 Y$ post-vac & 114 & 89 (81.3-93.8) & $50.8(38.8-66.5)$ & \\
\hline
\end{tabular}

hSBA, serum bactericidal assay using human complement; $\mathrm{Cl}$, confidence interval; GMT, geometric mean titer; GMR, geometric mean ratio; M, month; post-vac, postvaccination with four MenACWY-CRM doses; Y, year.

a) One-year vs. 1-month post-vaccination GMT ratio. 
Supplementary Table 2. Summary of rSBA immunogenicity results (rSBA full analysis set)

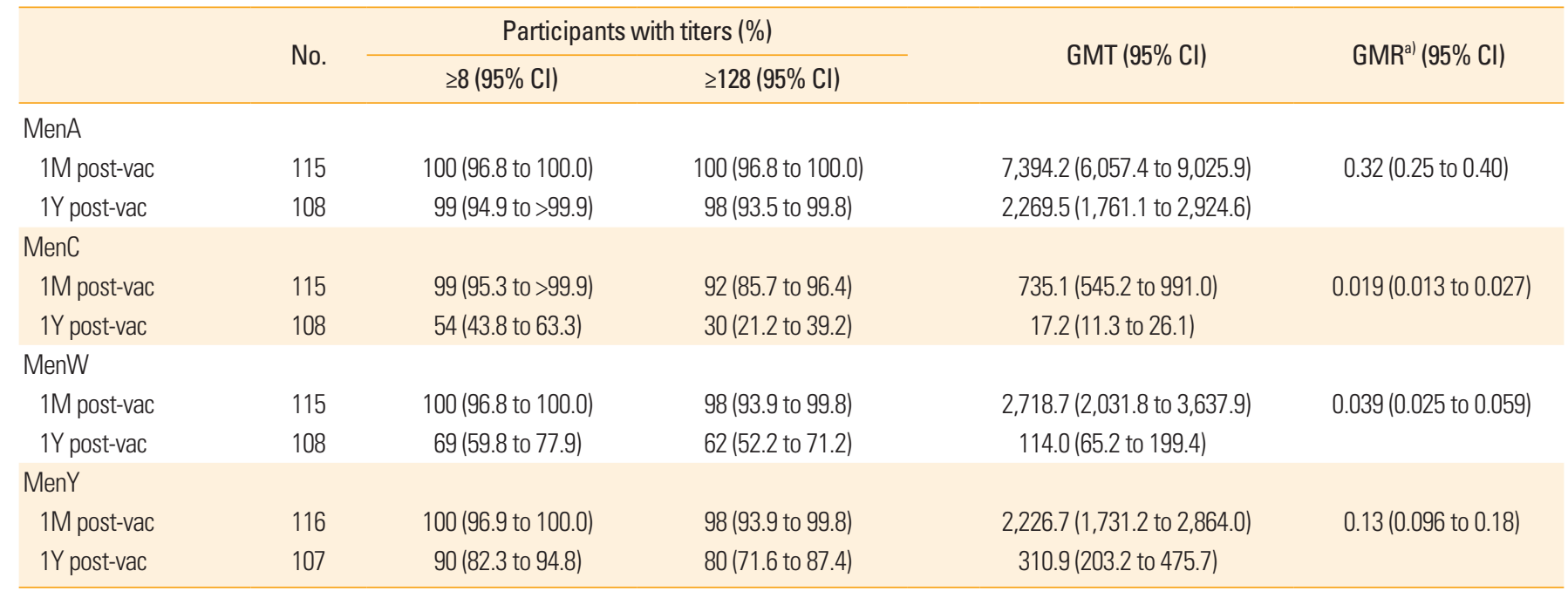

rSBA, serum bactericidal assay using rabbit serum; Cl, confidence interval; GMT, geometric mean titer; GMR, geometric mean ratio; M, month; post-vac, post-vaccination with four MenACWY-CRM doses; Y, year.

${ }^{\text {al } O n e-y e a r ~ v s . ~ 1-m o n t h ~ p o s t-v a c c i n a t i o n ~ G M T ~ r a t i o . ~}$ 
Hoan-Jong Lee et al • One-year antibody persistence following MenACWY-CRM vaccination in South Korean infants

Supplementary Table 3. Summary of immunogenicity results for the per-protocol set

\begin{tabular}{|c|c|c|c|c|c|c|c|}
\hline & \multicolumn{3}{|c|}{$\mathrm{hSBA}$} & \multicolumn{4}{|c|}{ rSBA } \\
\hline & No. & $\begin{array}{c}\text { Participants with } \\
\text { titers }(\%)\end{array}$ & $\begin{array}{c}\text { GMT } \\
(95 \% \text { CI) }\end{array}$ & No. & \multicolumn{2}{|c|}{$\begin{array}{c}\text { Participants with } \\
\text { titers }(\%)\end{array}$} & $\begin{array}{c}\text { GMT } \\
(95 \% \text { CI) }\end{array}$ \\
\hline \multicolumn{8}{|l|}{ MenA } \\
\hline $1 \mathrm{M}$ post-vac & 97 & 95 (88.4 to 98.3 ) & 123.7 (96.6 to 158.5$)$ & 91 & $100(96.0$ to 100.0$)$ & $100(96.0$ to 100.0$)$ & $7,307.5(5,800.1$ to $9,206.7)$ \\
\hline $1 \mathrm{M}$ post-vac & 97 & 99 (94.4 to >99.9) & 234.6 (181.3 to 303.4) & 91 & 100 (96.0 to 100.0$)$ & 95 (87.6 to 98.2) & 866.0 (633.8 to 1,183.2) \\
\hline $1 Y$ post-vac & 92 & 64 (53.5 to 73.9$)$ & 14.6 (10.5 to 20.3) & 88 & 58 (47.0 to 68.4) & 33 (23.3 to 43.8) & 20.6 (12.9 to 32.8 ) \\
\hline \multicolumn{8}{|l|}{ MenW } \\
\hline $1 \mathrm{M}$ post-vac & 97 & 100 (96.3 to 100.0$)$ & 459.9 (353.1 to 599.0) & 91 & $100(96.0$ to 100.0$)$ & $99(94.0$ to $>99.9)$ & $2,997.3(2,159.2$ to $4,160.6)$ \\
\hline
\end{tabular}

hSBA/rSBA, serum bactericidal assay using human/rabbit complement; Cl, confidence interval; GMT, geometric mean titer; M, month; post-vac, post-vaccination with four MenACWY-CRM doses; Y, year. 
Supplementary Table 4. Listing of serious adverse events from day 0 to study end, by system organ class and preferred term (overall safety set)

\begin{tabular}{lc}
\hline $\begin{array}{l}\text { Serious adverse event, by system organ class and } \\
\text { preferred term }\end{array}$ & Occurrence \\
\hline Congenital, familial and genetic disorders & \\
Buried penis syndrome & 1 \\
Gastrointestinal disorders & 1 \\
Enteritis & \\
Infections and infestations & 6 \\
Bronchiolitis & 1 \\
Croup infectious & 1 \\
Gastroenteritis & 1 \\
Hand-foot-and-mouth disease & 1 \\
Herpangina & 1 \\
Pharyngitis & 1 \\
Pharyngotonsillitis & 5 \\
Pneumonia & 1 \\
Pneumonia influenzal & 1 \\
Pneumonia parainfluenzae viral & 1 \\
Pneumonia respiratory syncytial viral & 1 \\
Pneumonia viral & 1 \\
Tonsillitis & 1 \\
Upper respiratory tract infection & 1 \\
Urinary tract infection & 1 \\
Viral infection & 1 \\
Injury, poisoning, and procedural complications & 1 \\
Contusion & 1 \\
Ligament rupture & 1 \\
Tendon injury & 1 \\
Cholesteatoma & 1 \\
\hline Nervous system disorders & 1 \\
\hline
\end{tabular}


Hoan-Jong Lee et al • One-year antibody persistence following MenACWY-CRM vaccination in South Korean infants
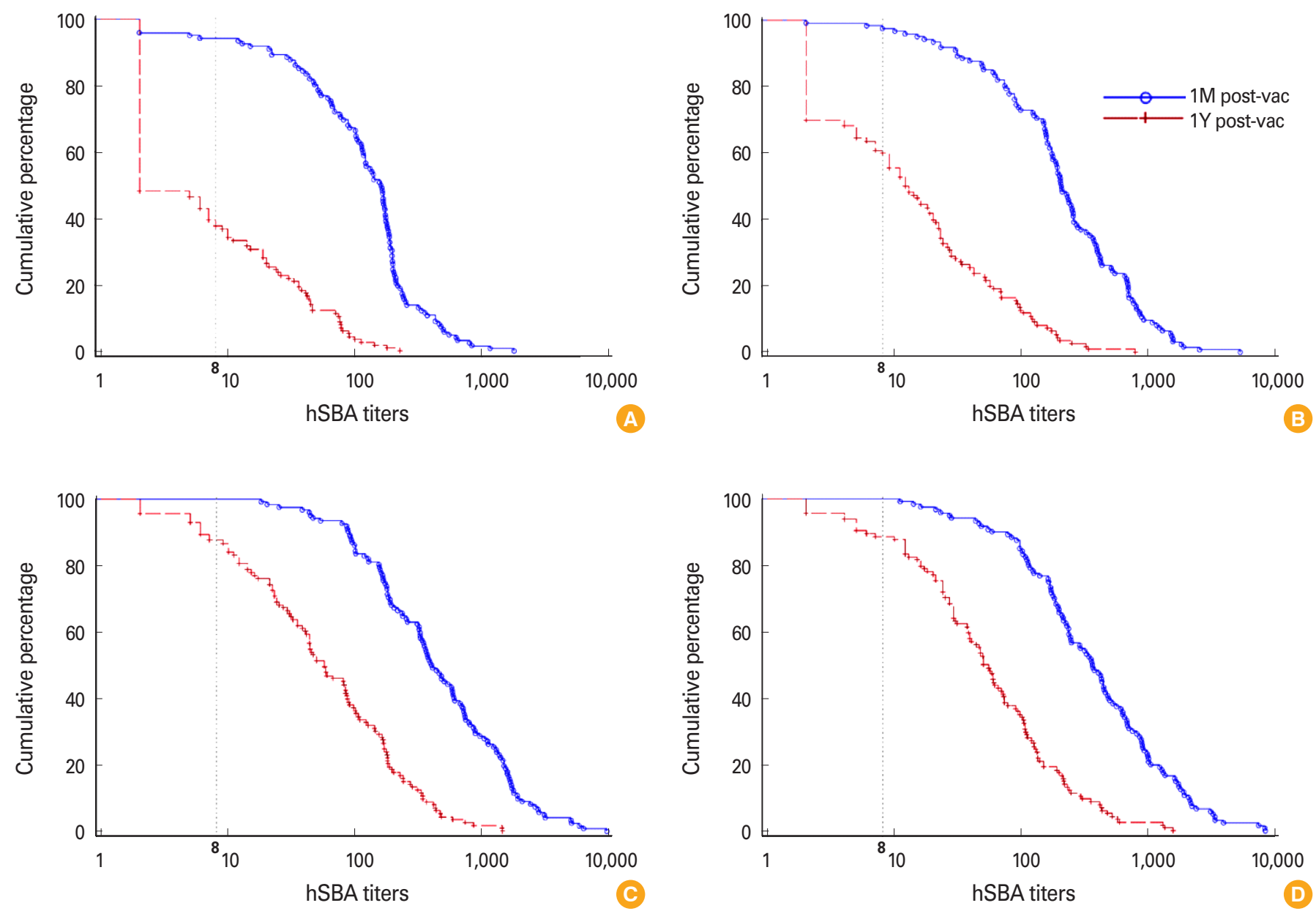

Supplementary Fig. 1. Reverse cumulative distributions of hSBA titers (full analysis set). (A) MenA. (B) MenC. (C) MenW. (D) MenY. hSBA, serum bactericidal assay using human complement; $\mathrm{M}$, month; post-vac, post-vaccination with four MenACWY-CRM doses; $Y$, year. 

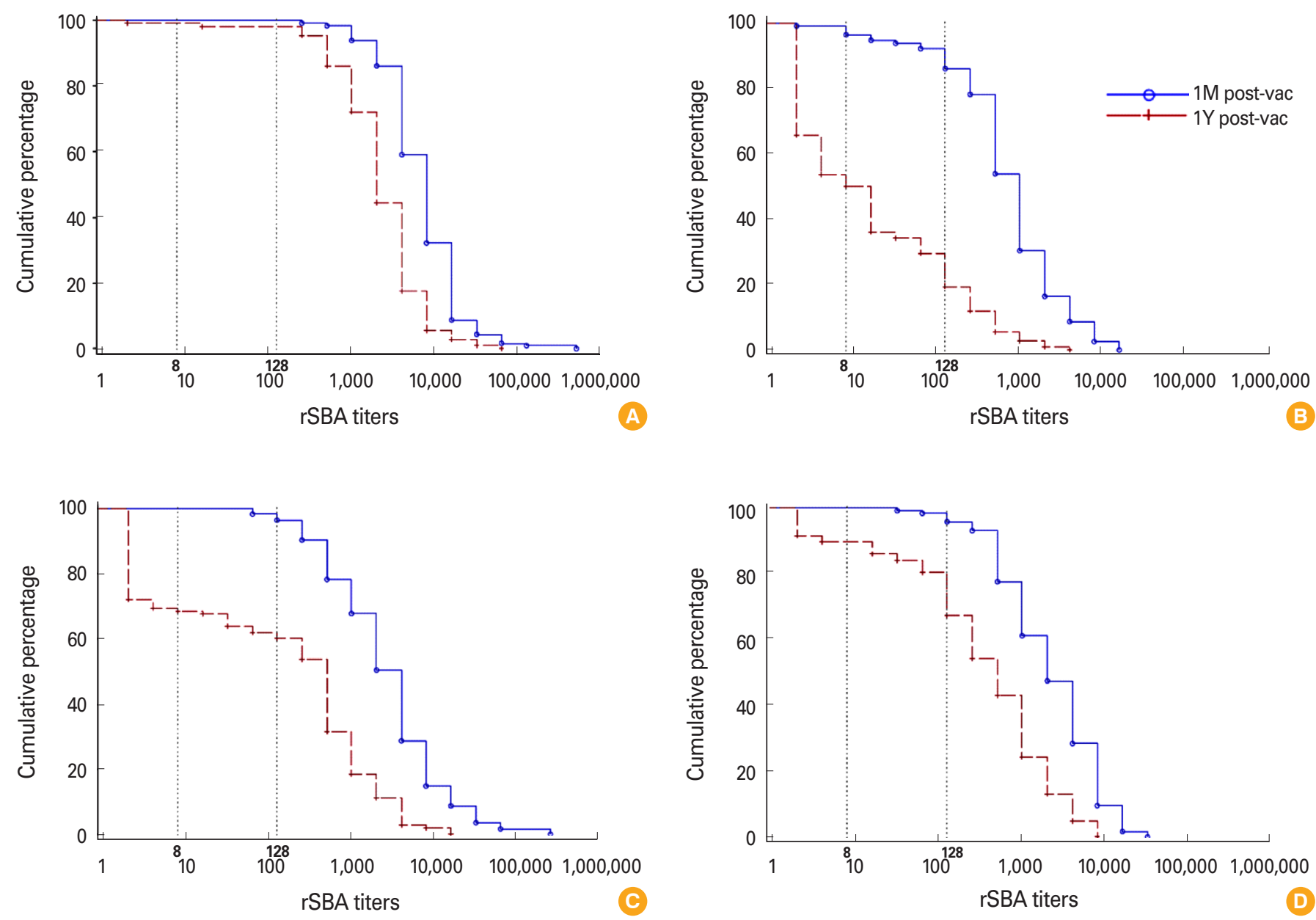

Supplementary Fig. 2. Reverse cumulative distributions of rSBA titers (full analysis set). (A) MenA. (B) MenC. (C) MenW. (D) MenY. rSBA, serum bactericidal assay using rabbit complement; $\mathrm{M}$, month; post-vac, post-vaccination with four MenACWY-CRM doses; $Y$, year. 